\title{
VIII.
}

\section{Ein Fall von Abscess des Rückenmarks nebst retrobulbärer Nenritis.}

\author{
Von \\ Dr. J. Silfrast, \\ Assistent an der Universitäts-Augenklinik in Helsingfors.
}

(Mit Tafel IX.)

In Anbetracht des sehr seltenen Vorkommen von Rückenmarksabscessen - bis jetzt sind nämlich, wie aus einer jüngst erschienenen Arbeit von Chiari ${ }^{1}$ ) hervorgeht, insgesammt acht selbständige hämatogene, nicht durchaus absolut sichere Fälle publicirt - darf ich mir vielleicht erlauben einen neuen solchen Fall mit ganz charakteristischem Krankheitsbilde zu veröffentlichen. Dazu kommt noch, dass unserer Fall mit einer interessanten Complication, nämlich einer auf einer retrobulbären Neuritis beruhenden vollständigen Erblindung complicirt war.

Der Kranke, ein 30jähriger Tagelöhner, wurde am 2. April 1900 in die hiesige Universitäts-Augenklinik aufgenommen. Laut seinen eigenen Angaben soll er bis vor ungefähr einem Jahre ganz gesund gewesen sein, aber seit der Zeit fing er an, dann und wann an Kopfschmerzen zu leiden. Die Schmerzen, welche er immer in der Stirngegend fühlte, waren niemals von grösserer Intensität, dauerten etwa einen Tag fort nnd erschienen anfangs erst nach mehrwöchentlichen freien Intervallen wieder. In der letzten. Zeit sollen doch die Schmerzen öfters etwa wöchentlich wiedergekehrt sein. $A b$ und $\mathrm{zu}$ litt $\mathrm{er}$ anch an heftigen Hustenanfällen. Sehstörrungen irgend welcher Art soll er nie gehabt haben.

Der Patient ist verheirathet, aber kinderlos. Lnes wird bestimmt geleugnet, ebenso Missbrauch von Alkohol und Tabak. Die Familienverhältnisse zeigen nichts Bemerkenswerthes dar.

Am 28. März Abends, nachdem er von einer mehrstündigen Schlittenfahrt bei sehr niedriger Aussentemperatur zurückgekehrt war, bekam er einen Anfall von heftigen Kopfschmerzen und bemerkte zugleich, dass es ihm neblig vor den Augen wurde. Es schien ihm, als ob das Zimmer voll Rauch wäre, oder als ob ihm ein Schleier vor den Augen hinge. Während des nächsten Tages nahm die Verschlechterung des Sehvermögens allmählich zu, doch konnte der Patient noch am 30. März v. M. sich auf eigene Hand

1) Chiari, Ueber Myelitis suppurativa bei Bronchiektasie. Zeitsehrift für Heilkunde 1900. Bd. XXI. 
bewegen. Vom 31. März an war und verblieb er vollständig erblindet. In den letzten Tagen soll er auch heftige Schmerzen in den Augen gehabt haben, und die Augen druckempfindlich gewesen sein.

Von seinem Status praesens beim Eintritt ins Krankenhaus sei Folgendes hier angefïhrt.

Der Patient ist ziemlich zart gebaut und schlecht genährt. Bei Untersuchung der inneren Körperorgane kann nichts Besonderes eruirt werden. Die Körperwärme normal; der Harn klar, frei von Zucker und Eiweiss.

Die Bewegungen der Augen sind in allen Richtungen eingeschränkt und schmerzhaft. Besonders giebt der Patient heftige Schmerzen an, wenn man die Angen in die Orbitae zurückzudrängen versucht. Aeusserlich sind die Augen normal, nur die Pupillen sind stark erweitert und reaktionslos. bie Augenmedien sind klar, der Augenhintergrund zeigt ausser einer vermehrten Füllung der Netzhantvenen und geringfügiger Hyperämie der Papillen nichts Besonders. $\nabla=0$.

Diagnose: Neuritis retrobulbaris ocul. amb.

Behandlung: Hydrargyrum per os. Blutentziehung am Processus mastoideus.

13. April. Der Patient giebt heute an, dass die spontanen Schmerzen in den Augenhöhlen etwas nachgelassen haben, und dass die Bewegungen der Augen weniger schmerzhaft sind. Ophthalmoskopischer Befund unverändert.

14. April. Der Patient meldet, dass sein linkes Bein seit gestern etwas kraftlos geworden ist. Objectiv kann doch nichts Bemerkenwerthes nachgewiesen werden.

16. April. Beim Gehen sieht man heute eine deutlich ausgeprägte Parese des linken Beines. Patient rotirt dasselbe dabei in einem leichten Bogen nach auswärts. Die Fussspitze streift am Boden. Die Mnskelkraft ist in hohem Grade herabgesetzt, der Patellarreflex merkbar verstärkt, die Haut etwas hyperästhetisch. Der Wärme- und Kältesinn scheint intact zu sein. Rechts dagegen besteht eine bedeutende Anästhesie und Analgesie des ganzen Beines und des Rumpfes bis etwa zur Nabelhöhe. An diesen Theilen ist der Wärme- und Kältesinn ganz erloschen. Die Muskelkraft scheint intact zu sein, der Patellarreflex schwach. mässig.

Das Sensorium frei. die Temperatur normal. Puls kräftig und regel-

17. April. Der Patient giebt an, dass er sein rechtes Bein nicht mehr so gat wie früher bewegt und den Harn nur mit Mühe lassen kann. Auf Aufforderung kann or unter Anstrengung aller seiner Kräfte das linke Bein im Hüft- und Kniegelenk unbedeutend biegen. Uebrigens ist der Befund derselbe, wie am vorigen Tage.

18. April. Seit der letzten Nacht Retentio urinae und Obstipatio. Vollständige Verlahmung der unteren Körperhälfte mit erloschenen Sehnenreflexen und Anästhesie bis etwa oberhalb des Nabels.

19. April. Gestern Abend stellten sich heftige Schmerzen in den oberen Extremitäten ein. Die rohe Kraft der oberen Extremitäten ist bedeutend herabgesetzt. Die Anästhesie und Analgesie der unteren Körperhälfte reicht etwa bis zu den Brustwarzen. An der ulnaren Seite der Unterarme eine geringfügige Herabsetzung der Tastempfindung. Die Reflexe der oberen and unteren Extremitäten erloschen. In den Mm. pec- 
torales fibrilläre Zuckungen. Die Wirbelsäule ist nirgends druckempfindlich. Keine Genickstarre. Die Gehirnnerven intact. Die Bewegungen der Bulbi frei nach allen Richtungen und schmerzlos. Die Amaurose besteht fort. Ophthalmoskopisch unverändert. Puls kräftig, regelmässig, ca. 80 Schläge.

20. April. Die Beweglichkeit des Kopfes ist ungestört. Der Patient, der eine passive Rückenlage einnimmt, kann mit grosser Anstrengung seiner Kräfte nur eine unbedeutende Flexion der Ellenbogenund Handgelenke hervorbringen. Die passiven Bewegungen sind frei. Keine bulbären Symptome. Die Athmung angestrengt und etwas beschlennigt, dann und wann von Husten unterbrochen, die Expectoration sehr mühevoll. Der spärliche Auswurf besteht aus zähem Schleim, der innig mit dunkelm Blute gemischt ist. Die Körperwärme, die in den vorigen Tagen nur etwas erhöht war, stieg zu $39,9^{\circ} \mathrm{C}$. Der Puls ist ziemlich kräftig, regelmässig, etwa 120 Schläge. Sensorium frei, ophthalmoskopischer Befund unverändert.

Der Patient wurde um $6 \mathrm{Jhr}$ Nachmittags in die Nervenabtheilung des Herrn Professor Homén überführt und wurde da folgendes notirt.

Patient nimmt eine passive Rückenlage ein, Athmung beschleunigt, Sensorium frei, klagt über Kopfschmerzen. Augenbewegungen normal nach allen Richtungen. Die Pupillen erweitert, reactionslos. $V=0$. Gehörund Geruchsempfindung normal, Keine Störung der Kaumuskeln und der vom Nerv. facialis innervirten Muskeln. Zungenbewegungen frei. Die Bewegungen des Kopfes sind ungestört. Die Sensibilität im Gesichte nicht alterirt Der Patient vermag unter Anstrengung aller seiner Kräfte eine ganz unbedeutende Flexion der Ellenbogen und Handgelenke hervorzubringen. Die unteren Extremitäten sind vollständig gelähmt, auch vermag er keine Bewegungen des Rumpfes auszuführen. Es besteht vollkommene Analgesie des unteren Körpertheils bis etwa zur 3. Rippe. Die Tast- und Schmerzempfindung an der ulnaren Seite der Hände und Unterarme ist bedeutend herabgesetzt; scheint dagegen normal zu sein an der radialen Seite der Hände und Unterarme nebst Oberarmen. Die Sehnenreflexe sind ganz erloschen, Cremasterreflexe lebhaft. Die Vertebra prominens etwas druckempfindlich. Retentio urinae et alvi. Die inneren Organe bieten nichts Nennenswerthes dar. Zur Zeit spürt der Patient nirgends Schmerzen. Temperatur $39,6^{0}$. Der Puls ist ziemlich kräftig, regelmässig, etwa 120 Schläge.

21. April Vormitt. Oberhalb der analgetischen Zone in der Höhe der 3. Rippe folgt eine etwa 2-3 fingerbreite Partie mit herabgesetzter Tastempfindung nnd darauf eine etwas schmälere byperästhetische Zone. Aehnliche Verhältnisse bieten die Wärme- und Kälteempfindungen dar. Uebrigens gleicher Befund wie gestern. Temp $39,5^{\circ}$.

Auf Grund des rapiden Verlaufes und des Krankheitbildes überhaupt schien es, dass der Fall am ehesten als ein Rückenmarksabscess aufgefasst werden müsste.

Unter allmählichem Sinken der Kräfte und Zunahme der Athembeschwerden trat gegen $5 \mathrm{Uhr}$ Nachm. Exitus ein.

Aus der 3 Stunden naeh dem Tode vom Herrn Professor Homén bei Gasbelenchtung ansgeführten Section sei Folgendes erwähnt: Die Muskeln im Allgemeinen schwach entwickelt, doch ohne auffallende Atrophien. Der Schädel von mittlerer Dicke, ziemlich symmetrisch. Diploë reichlich vorhanden. Die Dura mater etwas gespannt, die Gyri dureh dieselbe deutlich sichtbar. Die Pia mater unbedeutend ödematös, leicht ablösbar. Die 
Gefässe an der Schädelbasis dünn und glatt. Uebrigens ist an der Schädelbasis nichts Bemerkenswerthes nachweisbar. Die Schnittfläche des Gehirns glänzend, mässig blutpunctirt, die Ventrikel leer, das Epemdym glatt. An der Schnittfläche des Pons, der Mednlla oblongata und der Sehnerven ist nichts Besonderes zu bemerken. Die Dura mater in der Gegend der Halsanschwellung und in dem obersten Theil des Dorsalmarks leicht an dem Rückenmark adhärent. Die Meningen am ganzen Halstheil wie am obersten Brusttheil lebhaft injicirt. Die Gegend im Bereiche der 4.-7. Cervicalsegmente scheint dicker zu sein als normaliter. In den obersten Cervicalsegmenten hebt sich auf Querschnitten die graue Substanz nicht ganz scharf ab. Beim Einschnitt in das 4. Cervicalsegment quillt aus dem Centrum eine grünliche, eitrige Flüssigkeit hervor. Auf dem Querschnitt der 6.-8. Cervical- und 1. Dorsalsegmente findet man in den centralen, wie in den angrenzenden Partien namentlich nach links zu eine blatig eitrige Erweichung des Gewebes. Nach unten zu nimmt die Ansbreitung der erweichten Partien allmählich ab, und etwa von der Mitte des Dorsalmarks an ist nichts Pathologisches mehr nachweisbar.

Die Lungen sind an der Brustwand angewachsen. Im obersten Lappen der rechten Lunge ein etwa pflaumengrosser Hohlraum mit käsig-eitrigem Inhalt, und theilweise zerfallenden Wandnngen, in welchen hier und da weissgraue und weissgelbe, miliare Knötchen sichtbar sind. Knötchen gleicher Art sind sehr reichlich an verschiedenen Stellen des oberen und mittleren Lappens vertreten, in geringerer Zahl ebenfalls im untersten Lappen. Sie stehen theils einzeln neben einander, theils sind sie mit einander verschmolzen und theilweise von festem fibrösen Gewebe umgeben. Ausserdem treten im untersten Lappen grauröthliche pnenmonische Herde hervor. In der linken Lunge eine geringe Zahl miliarer Knötchen, sonst nichts Besonderes. In den Bronchien eine reichliche Menge schleimig eitrigen Secretes. Die Bronchialdrüsen geschwollen und zum Theil käsig zerfallen. Im Coecum und im untersten Theil des Ileum befinden sich einzelne kleine oberflächliche Geschwüre, in deren unebenen nnd etwas erhabenen Rändern einzelne im Zerfall begriffene weissgelbe, miliare Bildungen vorhanden sind. Die Follikel im unteren Theil des Ileum etwas geschwollen, die Schleimhaut übrigens glatt, hier und da injicirt. Die übrigen Organe zeigen nichts Besonderes.

Von verschiedenen Segmenten des Rückenmarks, von der Gehirnoberfläche, vom rechten Sehnerven und Bulbus, wie vom Herzblute wurden anaërobe- und aërobe Culturen angelegt. Das Rüickenmark, Gehirn, rechter Bulbus und rechter Sehnerv wurden in Müller'sche Flüssigkeit gesetzt, der linke Sehnerv nebst Bulbus in 10 proc. Formollösung.

Sämmtliche Gulturen verblieben steril.

Die einzelnen zur mikroskopischen Untersuchung entnommenen Stücke warden in Celloidin eingebettet.

\section{Mikroskopische Untersuchung.}

Untersucht wurden: das Rückenmark nebst Medulla oblongata, die beiden Sehnerven und Bulbi, das Chiasma und die Tractus optici.

Die Färbung erfolgte nach Weigert, Weigẹt-Pal, mit Säurefuchsin, mit Delafield'schem Hämatoxylin nnd Eosin, nach van Gieson, Nissl, mit Löffler'schem Methylenblau und nach Gram-Weigert.

Deutsche Zeitschr, f. Ner venheillunde. XX. Bd. 
In der Medulla oblongata und in den beiden obersten Cervicalsegmenten finden wir normale Verhältnisse ausser Spuren einer leichten beginnenden, secundären Degeneration in den Hintersträngen.

Schnitte aus den beiden darauffolgenden Cervicalsegmenten zeigen in der centralen grauen Substanz einen ziemlich scharf umschriebenen aus poly- und mononucleären Leukocyten nebst körnigem Detritus gebildeten Herd, durch welchen der Centralkanal verwischt worden ist. In der Umgebung des Herdes vereinzelte Lenkocyten.

Das fünfte Cervicalsegment zeigt ausser einem ähnlichen Herd, wie in den genannten Segmenten, in der centralen grauen Substanz eine ziemlich dichte leukocytäre Infiltration des linken Hinterhornes. Kleinere Anhäufungen solcher Zellen finden sich ausserdem in den angrenzenden Partien der weissen Substanz. Die Septa der eben erwähnten Partien sind kleinzellig infiltrirt und die Gefässe ziemlich stark blutgefüllt. Die Gefässwände und das perivasculäre Gewebe kleinzellig infiltrirt.

In dem sechsten Cervicalsegment sind ausser den auch im vorigen Segmente alterirten Partien noch das linke Vorderhorn und ein grosser Theil der Hinterstränge infiltrirt. Auch hier hat die Infiltration überwiegend einen diffusen Charakter. Hier und da, besonders im rechten Vorderhorn und in den Hintersträngen treten jedoch dichte Anhäufungen von Leukocyten hervor. Etwa in der Mitte des rechten Hinterstranges und den angrenzenden Theilen des Hinterhornes ist das Rückenmarksgewebe in bedentendem Umfange durch eine structurlose, eine Fibrinfärbung nicht annehmende Masse nebst Kleinzellen ersetzt. Blutungen, zum Theil von bedeutendem Umfang, sind an verschiedenen Stellen des Querschnittes vorhanden. Die Blutgefässe and ihre perivasculären Räume zeigen ein ähnliches Bild wie die des vorigen Segmentes.

In dem siebenten Cervicalsegment tritt die Alteration der weissen Substanz in den Vordergrund. Hier sind nämlich die Nervenfasern nebst Neuroglia an vielen Stellen und insbesondere der Hinterstränge und des linken Seitenstranges meistentheils ganz zerfallen und zerstört, wodurch Hohlräume verschiedener Grösse entstanden sind, die körniges Exsudat, Nervenfaserreste und Blutkörperchen enthalten. Ein kleiner Hohlraum ist ausserdem im rechten Vorderhorn vorhanden. Der äussere Theil des linken Vorderhorns ist in eine körnige, infiltrirte Masse umgewandelt. An mehreren Stellen befinden sich grosse Anhänfungen von rothen Blntkörperchen. Besonders verdient das rechte Hinterhorn in dieser Beziehung hervorgehoben zu werden. Die Blutgefässe sind stark erweitert und strotzend mit Blut gefïllt. Die perivascalären Räume treten stellenweise wie breite, die Gefässe einschliessende Blutsäulen hervor. Die Meningen sind hyperämisch aber sonst nicht alterirt.

Das achte Cervicalsegment zeigt ein ziemlich ähnliches Bild wie das vorige Segment.

Im ersten Dorsalsegment hat die Alteration und der Untergang des Gewebes einen noch höheren Grad erreicht. So ist an der linken Seite des Querschnittes nur eine schmale Randzone einigermassen intacter Nervensubstanz vorhanden (s. Fig. 1 auf Tafel IX). An der weniger lädirten rechten Seite hat die Gewebsalteration einen mehr umschriebenen Charakter. In der weissen Substanz der linken Seite befinden sich mehrere kleine Hohlräume, die ein lockeres Gefüge von zerfallenem Nervengewebe nebst 
weissen und rothen Blutkörperchen enthalten. An verschiedenen Stellen des Querschnittes massenhafte Blutungen. Die Blutgefässe und die perivasculären Räume gleichen denen des vorigen Segments.

In den nach Gram-Weigert oder mit Löffler'schem Methylenblan gefärbten Schnitten tritt vor Allem an der linken Seite eine sehr reiche Anhäufung von Kokken hervor. Sie liegen theils in kleineren und grösseren Haufen, theils in Diploform oder in längeren Ketten angeordnet. Der grösste Theil der einzelnen Kokken hat die runde Form verloren, ist klumpig, ungleich gross und unregelmässig, sowie ungleichmässig gefärbt (s. Fig. 2 Tafel IX). An mehreren Stellen sind sie za einer formlosen körnigen Masse zerfallen, in der sich jedoch typische Ketten und Uebergangsformen zu denselben erkennèn lassen.

Im zweiten Dorsalsegment ist die centrale graue Substanz, der grösste Theil der Vorderhörner, die Basis der Hinterhörner und die angrẹnzenden Theile der weissen Substanz in eine structurlose, kleinzellig infiltrirte Detritusmasse umwandelt. Die Gefässwände und Scheiden sehr reichlich kleinzellig infiltrirt. In und zwischen den Meningen rothe Blatkörperchen in ziemlich grosser Menge.

Im dritten Dorsalsegment sind die Vorderhörner nebst den angrenzenden Theilen der Vorderstränge in Hohlräume umwandelt, die vorwiegend mit einem structurlosen, eine Fibrinfärbung nicht annehmenden Exsudat gefüllt sind. Daneben hier und da im Querschnitt Anhäufungen von Rundzellen und rothen Blutkörperchen.

In der centralen granen Substanz des vierten Dorsalsegments ein scharf nmgrenzter aus Leukocyten, rothen Blutkörperchen nebst zerfallenen Gewebsresten gebildeter Herd. Nach rechts von diesem ein ziemlich grosser mit körnigen Massen gefüllter Hohlraum. Der laterale Theil des linken Vorderhorns ist stark zellig infiltrirt. In Präparaten von dem fünften Dorsal- bis zim zweiten Lumbalsegment findet man einen ähnlichen, aber weniger ausgeprägten Herd, wie im dritten nnd vierten Cervicalsegment. Ebenso wie in den Hintersträngen der oberen Cervicalsegmente findet man auch hier, namentlich links, in der Pyramidenseitenstrangbahn der dorsalen und lumbalen Segmente Spuren einer beginnenden secundären Degeneration.

Die mikroskopische Untersuchung der Sehnerven erweist an beiden eine reichliche, überwiegend diffuse Infiltration von Leukocyten, besonders reichlich in den Bindegewebssepten und um die Gefässe herum. Die Infiltration tritt ziemlich gleichmässig über dem ganzen Querschnitt hervor (s. Fig. 3 anf Tafel IX), und sind die beiden Sehnerven fast vollständig gleichartig davon betroffen. Infiltration geringen Grades findet man auch in der Pialscheide und in dem intervaginalen Lymphraume. Die Nervenfasern sind meistentheils an den resp. Querschnitten zerfallen. Die Intensität der Veränderungen ist im hinteren orbitalen Theile der Sehnerven am stärksten ansgeprägt und nimmt sowohl gegen die Bulbi wie gegen die Tractus zu allmählich ab. In dem Chiasma ist besonders hervorzuheben die reiche Kernvermehrung um die Gefässe herum. In den Tractus ist eine Infiltration kaum nachzuweisen. In der Sklera, Chorioidea und Retina, in der Umgebung des Sehnerveneintrittes sind keine Veränderungen zu sehen. 


\section{Epikrise.}

Im Verlaufe von 2 bis 3 Tagen entwickelte sich bei einem angeblich gesunden Menschen vollständige Erblindung beider Augen unter hochgradigen spontanen Schmerzen in der Stirngegend und in den Augenhöhlen. Bei Bewegungsversuchen der Augen steigerten sich dieselben. Ophthalmoskopisch nachweisbare Veränderungen, durch welche die Ursache der Erblindung aufgeklärt werden konnte, waren dabei nicht vorhanden. Dieses Kranheitsbild machte es in hohem Grade wahrscheinlich, dass die Erblindung auf Grund einer retrobulbären Neuritis entstanden sei. Eine Aetiologie konnte, wie es ja bei dieser Affection oft der Fall ist, nicht mit Sicherheit nachgewiesen werden. Als letzte Gelegenheitsursache konnte möglicherweise eine Erkältung angenommen werden. Die ersten Symptome traten ja unmittelbar nach einer längeren. Schlittenfahrt bei niedriger Temperatur ein. Zwei Wochen später, während die Erblindung auf der anfänglichen Stufe fortbestand, trat plötzlich Parese des linken Beins ein, um nach 2 Tagen ein ungefähr mit der Brown-Sequard'schen Spinallähmung ähnliches Krankheitsbild zu zeigen. Es bestand nämlich Parese des linken Beines mit erhöhten Sehnenreflexen und Hyperästhesie, unter gleichzeitigem Vorhandensein einer sensiblen Lähmung des rechten Beins. Nach weiteren 2 Tagen finden wir Paraplegie der unteren Extremitäten mit erloschenen Sehnenreflexen, completer Anästhesie der unteren Körperhälfte nebst Parese der oberen Extremitäten, d. h. ein Krankheitsbild, das zunächst an eine acut entstandene Unterbrechung der Leitungsbahnen oder an eine Affection denken liess, die anfänglich ihren Sitz an der linken Seite des Rückenmarks hatte, aber bald den grössten Theil des Querschnittes ergriff, und deren obere Grenze etwa bis zum mittleren oder oberen Theile der Intumescentia cervicalis reichte.

Infolge dieses Krankheitsverlaufes und Bildes wurde „Abscessus medullae spinalis" als Wahrscheinlichkeitsdiagnose von Professor Ho mén gestellt und auf eine ähnliche Noxe zurückgeführt, wie die der retrobulbären Neuritis. In analoger Weise ist ja, wie aus ziemlich vielen in der Literatur beschriebenen Fällen hervorgeht - s. z. B. die Zusammenstellung von K. Katz $\left.{ }^{1}\right)$ - eine Neuritis nerv. optici entstanden in Verbinding mit einer acuten Myelitis.

Gleichwie in unserem Falle stellte sich nämlich in diesen Fällen plötzlich und ohne direct nachweisbare Ursache bei anscheinend ganz gesunden Individuen eine rapide Abnahme des Sehvermögens ein, oft

1) K. Katz, Ueber das Zusammenvorkommen von Neuritis optica und Myelitis acuta. Archiv für Ophthalmologie. 1896. Bd. 42. 
unter heftigen Schmerzen in der Stirngegend und in den Augenhöhlen. Nach kürzerer oder längerer Zeit traten dann zu den Sehstörungen Symptome einer acuten Myelitis hinzu.

Die am Krankenbett gestellte Diagnose „Abscessus medullae spinalis" wurde durch die Section völlig bestätigt, man fand nämlich, vorzugsweise im centralen Theile des Rückenmarks einen vom 4. Cervical bis zu den obersten Dorsalsegmenten reichenden eitrigen Zerfall des Gewebes. Der negative Sectionsbefund an den Sehnerven ist wohl auf die Beleuchtung während der Section zu beziehen. Denn eine nur wenig ausgeprägte graue oder grauröthliche Verfärbung des Sehnervengewebes lässt sich bei Gasbeleuchtung wohl kaum nachweisen.

Die mikroskopische Untersuchung des Rückenmarks und der Sehorgane ergab eine ausreichende Aufklärung der klinischen Symptome.

Suchen wir nun nach einer gemeinsamen Ursache der beiden oben beschriebenen Affectionen, so haben wir mit grösster Wahrscheinlichkeit als solche den Hohlraum mit käsig-eitrigem Inhalt im obersten Lappen der rechten Lunge zu betrachten.

Gleichwie in den Fällen von Nothnagel ${ }^{1}$ ), Eisenlohr ${ }^{2}$ ), Homén ${ }^{3}$ ), und $\mathrm{Chiari}^{4}$ ) muss wohl auch in unserem Falle angenommen werden, dass die Mikroorganismen auf hämatogenem, embolischem Wege zu den erwähnten afficirten Organen transportirt worden sind. In unserem Falle dürfen wir vielleicht nicht die Möglichkeit ganz ausser Acht lassen, dass die kleinen tuberculösen Ulcerationen in den Därmen die Eingangspforte für die Mikroorganismen gebildet haben. Gleichwie der von Homén veröffentlichte Fall zeigt auch der unsere, dass die Meningen völlig intact bleiben können, wenn auch ein grosser Theil des Rückenmarkquerschnittes zerstört ist.

Die bacteriologische Untersuchung ergab in Schnitten aus dem am meisten alterirten Theile des Rückenmarks eine grosse Zahl freilich in Degeneration begriffener Gram- beständiger Mikroorganismen, die wohl als Streptokokken gedeutet werden müssen.

Als Krankheitserreger bei Rückenmarksabscessen sind früher nachgewiesen worden: kurze Stäbchen von Eisenlohr, Staphylokokken

1) Nothnagel, Ueber Rückenmarksabscess. Wien. med. Blätter. 1884.

2) Eisenlohr, Ueber Abscesse in der Medull. oblong. Deutsch. med. Wochenschr. 1892.

3) Homén, Un cas d'absces de la moëlle. Revue neurologique. 1894.

4) Chiari, Ueber Myelitis suppurativa bei Bronchiektasie. Zeitschr. f. Heilkunde. 1900. 
102 VIII. Silfvast, Ein Fall v. Abscess d. Rückenmarks n. retrobulbärer Neuritỉs.

(zwei Fälle) von Schlesinger ${ }^{1}$ ), Streptokokken von Homén und Diplococcus pneumoniae nebst einer Gattung Streptothrix von $\mathrm{Ch}$ iari.

Dass trotz negativem Ausfall des Züchtungsversuches doch Bacterien in Schnitten nachweisbar waren, giebt wiederum eine Stütze für die besonders von Homén experimentell erwiesene Thatsache, dass Bacterien, allerdings mehr oder weniger degenerirte in dem Rückenmarksgewebe einige Tage länger als in Culturen nachgewiesen werden können. Auf ähnliche Befunde habe ich auch selbst hingewiesen in meiner Arbeit über experimentelle Lungenentzündung.

Dass der Bacteriennachweis in den Sehorganen erfolglos sein würde, war schon a priori zu erwarten, es waren ja schon 25 Tage verstrichen zwischen dem Ausbruch der Sehstörung und dem Exitus.

\section{Erklärung der Abbildungen auf Tafel IX.}

Figur 1. Querschnitt aus dem ersten Dorsalsegment. Markscheidenfärbung nach Weigert.

Figur 2. Einzelne in Ketten angeordnete degenerirte Kokken aus der zerfallenen Partie des linken Seitenstranges derselben Region wie Fig. 1. Färbung mit Löffler'schem Methylenblau. Zeiss' homog. Imm. 1/12, Oc. 4.

Figur 3. Quersehnitt (ein Quadrant) aus dem hinteren orbitalen Theile des rechten Sehnerven. Färbung nach van Giesen. Zeiss' Obj. AA, Oc. 2.

1) Schlesinger, Ueber Rückenmarksabscess. Arbeiten aus dem Obersteiner'schen Laboratorium in Wien 1894 und Deutsche Zeitschr. f. Nervenheilkunde. 189 . 